\title{
Engagement and Disengagement in Online Service Failure: Contrasting Problem and Emotional Coping Effects
}

\author{
Sigi Goode \\ School of Accounting and Business Information Systems \\ College of Business and Economics \\ The Australian National University \\ Email: sigi.goode@anu.edu.au \\ Ph. +61261255048 \\ Fax. +61261255005
}

\begin{abstract}
Users are likely to cope with service loss depending on how integrated the services are. In this study, we manipulate the degree of service involvement by comparing users of highly integrated cloud storage services against users of low integration storage services. We find that users of high integration services are more likely to engage with the provider following service failure. When emotional coping mechanisms are used, both high and low integration users are equally prone to disengagement, but low integration users are significantly less likely to display engagement behaviors.
\end{abstract}

Keywords: engagement, service failure, coping, emotion 


\title{
Engagement and Disengagement in Online Service Failure: Contrasting Problem and Emotional Coping Effects
}

\begin{abstract}
Users are likely to cope with service loss depending on how integrated the services are. In this study, we manipulate the degree of service involvement by comparing users of highly integrated cloud storage services against users of low integration storage services. We find that users of high integration services are more likely to engage with the provider following service failure. When emotional coping mechanisms are used, both high and low integration users are equally prone to disengagement, but low integration users are significantly less likely to display engagement behaviors.
\end{abstract}

\section{Introduction}

Online services are a lucrative and popular business area. Practitioner evidence emphasizes the popularity of online services such as banking, search, auctions, social networking, and others (Vatanasombut et al., 2004). Numerous such services exist online, and patronage of these services can be significant for fulfilling a range of needs. This significant user patronage also means that users come to rely on these online services, depending on providers to supply particular services as agreed (Gartner Research, 2010). Users can become distraught and upset when these services are inaccessible or unavailable (Kuo et al., 2011; Wang et al., 2011; Kuo and $\mathrm{Wu}, 2012)$. Adverse user reaction to service failure is an important business problem, especially online, because of the ease with which users can switch online service patronage (Constantinides, 2004). Evidence from Ofcom (2010) shows how users can also switch between physical service providers based on their online service experiences. Providers typically encourage users to make the most of their services and to 
become highly integrated with the service, because this involvement and attachment improves the user base and, ultimately, business revenues (Collier and Bienstock, 2006; Holloway and Beatty, 2008). However, highly integrated users may be more likely to react badly when the service fails because they are so dependent on the service's offerings and continuity ( $\mathrm{Wu}$ and Lo, 2012). Understanding the coping reactions of these highly integrated users is hence an important business problem.

The online service context lends a new dimension to this problem, in that the service consumer is separated from the service provider and the service (Keh and Pang, 2010; Kuo and $\mathrm{Wu}, 2012)$. Whereas a face-to-face service consumer can complain to the service provider directly in the event of service failure, an online service user must cope on their own terms (Holloway and Beatty, 2003; Harris et al., 2006). While there has been much prior research in the psychology and marketing literatures on the subject of coping mechanisms, there has been only a small amount of prior coverage in information systems (e.g. Moynihan, 2002; Beaudry and Pinsonneault, 2005). While IS has seen a large amount of prior work into how users initially acquire and then use technology, very few studies have explored how users react when the technology is subsequently removed or becomes unusable. Coping, the personal strategies for overcoming stressful events (Pearlin and Schooler, 1978; Billings and Moos, 1981; Lazarus and Folkman, 1984), ought to be useful in understanding how users react when they are deprived of service fulfillment. However, few prior studies have applied a coping lens to online service loss. This is a significant gap in understanding, because use is one of the most popular topics in IS research and a significant amount of prior work has sought to understand the processes used to enact this technology adoption: however, we do not yet understand the mechanisms that users employ to deal with the loss of online services. 
This study aims to address this gap by exploring the effect of two coping mechanisms on user engagement and disengagement propensities. The study builds a model from prior psychology literature and applies this model to 360 users of cloud storage services. We contrast these coping mechanisms between two user groups: the first group uses services that only provide website access to their cloud storage. The second group uses highly integrated cloud services, providing desktop integration, mobile device app support as well as conventional website access. The study's research question is as follows.

How do problem-based and emotion-based coping affect engagement and disengagement following service loss?

The rest of this paper is structured as follows. The next section discusses coping mechanisms and engagement and disengagement behaviors. This is followed by a discussion of integration. The paper then details the research method, followed by data analysis, discussion and conclusions.

\section{Coping}

Personality is important in IS and underpins many of the models and theories, at the individual level, in prior literature. Some of these theories are founded upon older models of individual psychology, such as the theory of reasoned action (Fishbein and Ajzen, 1975) and the theory of planned behavior (Ajzen, 1991, 2002). A thread running through this prior literature is that individuals approach positive phenomena and avoid negative phenomena (Elliot and Thrash, 2002; Carver and Connor-Smith, 2010). Encountering negative phenomena can be stressful and, as a result, a rational individual aims to avoid or minimize this type of experience (Nes and Segerstrom, 2006). Negative phenomena produce cognitive stresses which confront the individual's ability to manage the situation (Kashdan et al., 2006). 
Stress is painful, uncomfortable and challenging and, as a result, requires strategies to overcome it (Weinstein et al., 2009).

The act of coping is the behavioral process of dealing with situational demands (Billings and Moos, 1981; Shiloh and Orgler-Shoob, 2006). Coping is an important personal mechanism for overcoming, managing or responding to challenging circumstances (Kashdan et al., 2006; Weinstein et al., 2009). Coping is often associated with diminishing or controlling negative outcomes or anticipations, and is a key mechanism by which individuals minimize the mental or physical stress described above (Kammeyer-Mueller et al., 2009; Carver and ConnorSmith, 2010). Coping provides emotional and cognitive benefits that allow the individual to temporarily or permanently reduce the potential negative impact of adverse events (Folkman and Lazarus, 1980; Folkman, 2010) or to return the situational circumstances back towards their own abilities to adapt (Shiloh and Orgler-Shoob, 2006). While coping mechanisms may be voluntary or involuntary, we focus on coping mechanisms that are within the individual's sphere of cognizance.

While there are numerous types and frameworks to capture individual coping styles (Endler and Parker, 1990), prior literature has treated coping largely as either behavioral or cognitive (Carver et al., 1989; Tobin et al., 1989). Probably the most common framework is the problem/emotion focus framework (Lazarus and Folkman, 1984; Forsythe and Compas, 1987). Problem-focused coping relates to addressing the cause or nature of the stress agent itself (Scheier et al., 1986). When an individual uses a problem-focused coping strategy, they apply mental procedures to evaluate and weigh appropriate courses of action in order to solve the negative situation before them (Folkman et al., 1986; Baker and Berenbaum, 2007). By invoking a methodical plan to solve the problem, the individual builds a cognitive defense against the stress agent that is founded on calculative perceptions of action (Heppner et al., 
1995), thereby reducing its apparent threat or reach. An example of this problem-focused coping mechanism might be a user reviewing their past credit card purchases in order to determine the point at which their financial details were stolen.

The second classification is emotion-focused coping, whereby the individual employs an affective response mechanism to the stress agent. This affectation may take a variety of forms, such as negative emotions (unhappiness, crying, depression), positive emotions (resilience, optimism, happiness) and others (Fredrickson and Branigan, 2003). Emotions provide a cushioning response for ameliorating the impact of negative events (Thoits, 1986). Other work has examined the use of coping to deal with positive affective events that impose some change on an individual's chosen or available courses of action (Folkman and Moskowitz, 2000, 2004; Fredrickson and Branigan, 2003). An example of an emotionfocused coping mechanism might involve worrying, or seeking social or familial support about the stress agent (Thoits, 1986). Emotional coping may allow the individual to deal with the stress agent more calmly, or to view it in a more positive light.

\subsection{Coping Outcomes}

Prior literature provides two important categorizations of coping outcomes, being engagement and disengagement. These outcomes provide a framework through which to understand the eventual effects and elaborations of the initial coping process. Engagement refers to an individual's desire or intention to unite with or revisit the stress agent (Charlton and Danforth, 2007). Engagement involves approaching the cause of discomfort with a view to correcting or redressing this cause (Miller and Kaiser, 2001). For instance, an engaged customer may confront the cause of stress, such as a business, with a view to altering the situation. Alternatively, they may seek information about the stress problem (Compas, 1998). 
There have been several examples of engagement elaborations in prior IS research. For example, Straub and Welke (1998) discuss the importance of engaging with end users in order to deal with security threats. Beaudreau and Robey (1996) used learning as a coping mechanism for business process reengineering inconsistencies, whereby cognitive strategies are used to obtain greater involvement with the problem. Benamati and Lederer (2001) discuss a type of indirect engagement in IT change, where firms employ consultants to solve the stress problem. Ren et al. (2008) describe processes of individuals and teams engaging in joint problem solving in coping with coordination problems in highly dynamic environments.

Disengagement involves avoiding or downplaying the stress agent, such that the individual moves away from the negative effects. Disengagement provides some distance between the individual and the stress, perhaps in the form or space, time or importance (Carver et al., 1989; Major and Schmader, 1998). Disengagement may be maladaptive in that individual does not change their behavior and, hence, the cause of the stress (and its harmful effects) might return or persist despite the coping mechanism (Carver and Scheier, 1994). However, disengagement might provide some respite for the individual, allowing them to gather their thoughts and feelings in order to alter future behavior (Hong, 2007). Prior psychology literature has argued that some types of disengagement can be emotionally and behaviorally costly because they fail to adequately deal with the causes of the stress, thereby allowing the stress to increase over time.

Some prior IS research has provided examples of disengagement. For instance Moynihan (2002) provided examples of IT project managers' reluctance to discuss project problems with clients. Savolainen (2007) describes personal disengagement behaviors in dealing with information overload: "people may cope with information overload by simply avoiding or ignoring the excessive supply of information". Some prior work also explores simultaneous 
engagement and disengagement behaviors. For example, Chesney et al. (2009) conduct focus groups to determine coping strategies for stress agents in virtual worlds. These strategies are both engaged (fighting back) and disengaged (ignoring or banning the stress agent).

\section{Functional Integration}

Integration represents the overall degree of interoperation between a system and its related processes (Avison et al., 2004). Higher integration generally implies a 'closeness' between the system and its surrounding processes, while lower integration implies a distancing or disconnection (Morash and Clinton, 1998). Prior IS literature has often applied functional integration in the organizational and commercial contexts (Wainwright and Waring, 2004), whereby integration occurs between an information system, comprising applications and their ICT platforms, and its associated business processes and channels (Cappiello et al., 2003). Highly integrated systems are strategically aligned within the architecture of business processes (Truman, 2000; Aerts et al., 2004), whereby the modules comprising these processes are closely interconnected, dependent and cohesive (Francalanci and Morabito, 2008).

Integration has been seen as both a positive and negative property of information systems in prior literature (Goodhue et al., 1992; Abel et al., 1994; Weber and Pliskin, 1996). On one hand, high integration can be useful because the higher interoperability between systems and processes yields benefits to transactions, data and information quality and lowers administration costs (Bergeron and Raymond, 1992; Elgarah et al., 2005; Narayanan et al., 2009). On the other hand, because highly integrated systems typically also have very high dependence on other processes in the organization, the process of initially integrating these systems is costly, risky and complex (Bygstad et al., 2010; Malhotra and Temponi, 2010). These integrative processes also require time to develop and adjust (Cappiello et al., 2003; 
Lam, 2005) because significant effort is expended on establishing module interoperability and the nature of the functional dependence (Wijnhoven et al., 2006). Accordingly, removing or changing these highly integrated systems is typically difficult because so many processes depend on the system for effective functioning (Barki and Pinsonneault, 2005). Over time, the organization comes to rely on these highly integrated systems, and removing them is hence a delicate process (Orlikowski, 1993; Markus, 2000).

Coverage of integration at the individual user level has tended to focus on the relationship between system interfaces and user behavior, such as user interface uniformity (Irani et al., 2003) and ease of use (Taha and Caldwell, 1993; Nicolaou, 2000). High integration systems can offer benefits to individual end-users because there are greater opportunities for interoperability with and assimilation into daily tasks (Liu et al., 2011). A wider range of system capabilities also provides greater capacity for task interoperability and cognitive dependence for individual end-users (Francalanci and Morabito, 2008; Lin et al., 2012). However, highly integrated systems may also pose concerns about individual privacy and data security (March and Hevner, 2007). Users may elect not to use these systems if they perceive that their activities within the system could harm their identity (Cazier et al., 2008) or compromise their personal locus of control (Brey, 2005).

At the individual level, as at the organizational level, it might be reasonable to suggest that the greater the level of integration offered by a system, the more the user will come to depend upon and need the system in their activities. When a system offers features that allow the user to insert the system into their practices and behaviors, the system becomes more vital to the user and their activities. As a result, a system that offers higher integration is more likely to be missed when it stops functioning: the user is no longer able to depend on the system for their activities. By contrast, systems that do not offer features that support integration are 
likely to see lower levels of assimilation. Users do not approach these systems in the same way as highly integrated systems because they know in advance that system functionality does not allow greater assimilation ex ante. Alternatively, users may seek out these low integration systems so that they do not have to depend on one provider for their services.

These types of system are hence also more easily replaced.

\section{Research Model and Hypothesis Development}

Figure 1 shows the research model. In summary, we argue that problem-focused coping and emotion-focused coping lead to engagement and disengagement behaviors. We hypothesize that these behavioral reactions will vary depending on the level of functional integration that each user experiences.

Figure 1 Research Model and Hypotheses

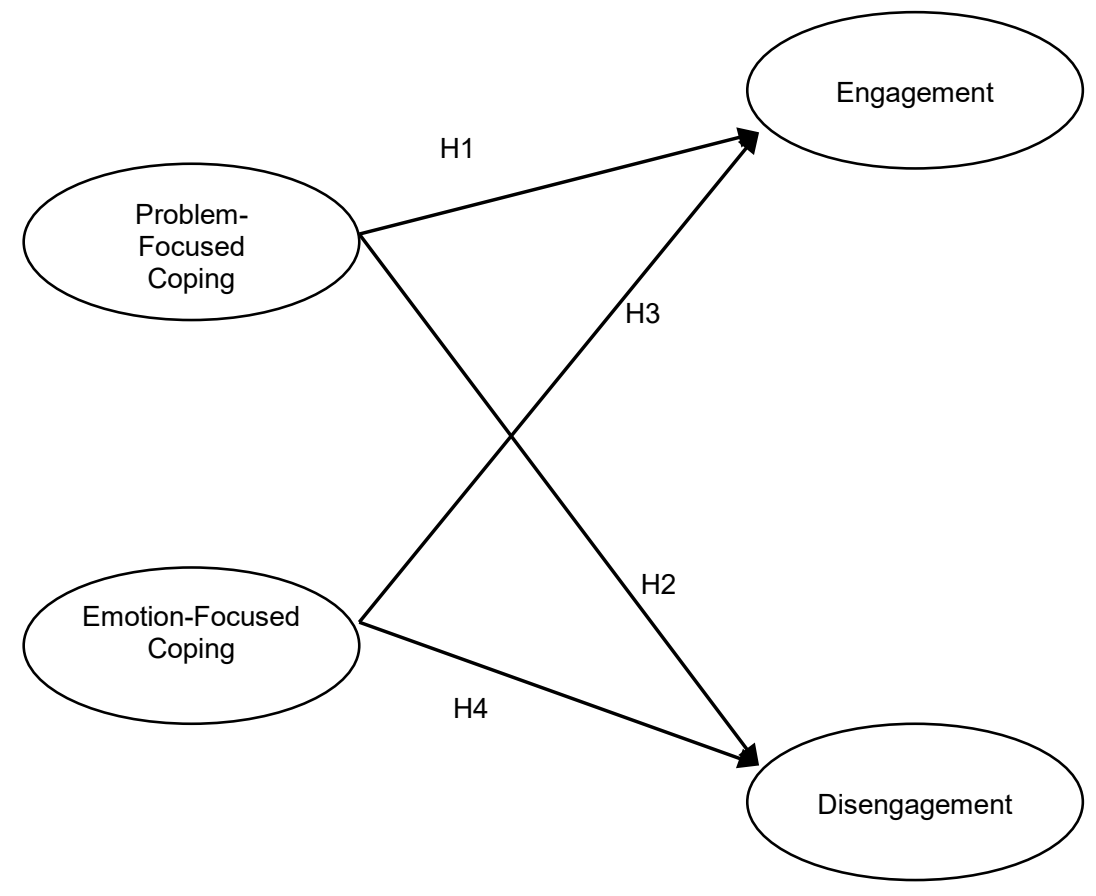

\subsection{Problem-focused Coping and Engagement}

Following prior research, we argue that there will be a positive relationship between problemfocused coping and engagement. In the case of volitional system use, a user is likely to want 
to work to correct the problem facing them (because the alternative is to voluntarily discontinue use). This leads to our first main hypothesis:

Hla. There is a positive relationship between problem-focused coping and engagement

Prior work has shown that cognitive coping approaches are likely to be employed when the individual feels that they are able to change the situation. Users of high integration services are likely to be more invested in service outcomes and hence will engage to a greater extent than users of low integration providers. Low integration users are better able to switch service providers and therefore engaging with a given provider is a less attractive and useful proposition. This leads to our first sub-hypothesis:

H1b. The relationship between problem-focused coping and engagement will be greater for high-integration users than low-integration users.

\subsection{Problem-focused Coping and Disengagement}

We argue that there will be a negative relationship between problem-focused coping and disengagement. Prior research has argued that problem-based coping involves gathering more information about the problem in order to attempt to solve or address it. In the online service context, parties cannot easily monitor each other's behavior and hence the information gathering process for problem-based coping is likely to be more extensive. In seeking out this cognitive fulfillment, the user is less likely to disengage. This leads to our second main hypothesis:

H2a. There is a negative relationship between emotion-focused coping and disengagement

Users of high integration services are less likely to disengage than users of low integration services. Users who are already invested in the service are more likely to want to protect their 
investment and hence are unlikely to disengage and hence forfeit their investment. By contrast, users of low integration services are better able to disengage because of the lower barriers to service switching. This leads to our second sub-hypothesis:

H2b. The relationship between problem-focused coping and disengagement will be lower for high-integration users than low-integration users.

\subsection{Emotion-focused Coping and Engagement}

There will be a negative relationship between emotion -focused coping and engagement. According to the approach-avoidance theory of personal behavior, individuals will prefer to avoid stressful and negative situations. If service failure is a negative event, then individuals are likely to want to avoid this emotional stress. Therefore, when a user copes emotionally, they are less likely to engage with the provider. This leads to our third main hypothesis is:

H3a. There is a negative relationship between emotion-focused coping and engagement

Low integration users are less likely to engage than higher integration users. Emotional coping is likely to lead to lower levels of engagement for users who can switch between service providers in order to avoid emotional upheaval. This propensity is higher for users of higher integration services because of the investment expectations they have made about the service. This leads to our third sub-hypothesis:

H3b. The relationship between emotion-focused coping and engagement will be lower for high-integration users than low-integration users.

\subsection{Emotion-focused Coping and Disengagement}

There will be a positive relationship between emotion-focused coping and disengagement. If the user wishes to avoid the stress-agent, then their emotional coping response will lead them to disengage with the situation. This leads to our fourth main hypothesis: 
H4a. There is a positive relationship between emotion-focused coping and disengagement

The propensity to disengage will be lower for high-integration users than lower integration users because the emotional coping mechanism could be stronger for higher levels of personal investment. This leads to our fourth sub-hypothesis:

H4b. The relationship between emotion -focused coping and disengagement will be lower for high-integration users than low-integration users.

\section{Research Method}

We used a questionnaire survey to collect our data because it allowed us to gather a variety of observations from a large number of disparately located respondents (Galliers, 1992). The survey is a popular data collection method in prior IS research (Straub, 1989; Grover et al., 1993; Palvia et al., 2003). In developing the survey, we used the advice of authors such as Dillman (1978; 2008) and Cooper and Schindler (2003) regarding structure and appearance. We adapted questionnaire items from prior studies in order to strengthen internal validity (Nunally, 1967). Items for capturing emotion and problem-based coping strategies were adapted from Yi and Baumgartner (2004), which has been applied in subsequent enquiries into service delivery and failure (Bhandari et al., 2007; Menon and Dubé, 2007; Gelbrich, 2010) and recently in the IS field (Beaudry and Pinsonneault, 2010). We adapted items for engagement and disengagement from prior coping-response studies (Dunkel-Schetter et al., 1987; Patterson, 2002).

We focused the instrument towards the use of cloud storage services. We provided a definition and examples of these cloud services at the outset of the survey. Respondents had to select the cloud services that they had used in the previous month, if any. The survey featured a list of 17 popular service providers. Respondents were also asked to identify any 
providers that they used that were not featured on the survey. We used a number of indicators to determine the level of functional integration offered by each service. Our overarching goal was to classify providers according to the degree to which they would interact with the user's operational activities. In determining this level of integration, we used prior definitions and conceptualizations of integration from Avison et al. (2004) and Nilsson et al. (1990). The procedure used for categorizing service providers is detailed in Appendix A. Respondents were directed to focus on the particular cloud service that they used most often.

To motivate the service failure component of the study, we used a similar approach to prior service failure studies such as Russell (1982), Hess et al. (2003) and Vázquez-Casielles et al. (2007). Respondents were asked to imagine that they had attempted to access their most-used cloud storage service but received no response from the server. The respondent was told that no alternative explanations were available and that there was no indication that the service would return at any time in the future. Respondents then had to signal their agreement or disagreement with the indicator questions, each on a seven point Likert scale.

\section{Results and Analysis}

In total, 420 people responded to the survey. We discarded 25 responses because of significant incompleteness and were left with 395 responses. We then sorted these responses according to the services they used, as in Appendix A. We discarded 35 responses from users who had only used those services that we omitted. This process left 360 useable responses. For the analysis stage, we had 249 high integration users and 111 low integration users.

Table 1 shows the demographic profile of the respondent group. Most respondents were male, for both groups. A quarter of respondents were female. With regard to age, the majority of respondents were between 20 and 30 years old, and the age distribution was reasonably consistent between groups. For low integration users, approximately $75 \%$ of respondents 
earned less than US $\$ 25,000$ per annum; by contrast, $75 \%$ of high integration users earned less than US\$50,000. This finding suggests that high integration users might be slightly more affluent than low integration users. With regard to the level of prior system use, figures were similar across the respondent groups and indicated a reasonable degree of prior exposure with cloud storage systems.

Table 1 Respondent Demographics

\begin{tabular}{|c|c|c|c|c|c|c|c|}
\hline \multirow{2}{*}{ Demographic } & \multirow{2}{*}{ Category } & \multicolumn{2}{|c|}{ High integration users } & \multicolumn{2}{|c|}{ Low integration users } & \multicolumn{2}{|c|}{ Full Sample } \\
\hline & & $\mathrm{n}$ & $\%$ & $\mathrm{n}$ & $\%$ & $\mathrm{n}$ & $\%$ \\
\hline \multirow[t]{3}{*}{ Gender } & Male & 185 & 74.3 & 77 & 69.4 & 262 & 72.8 \\
\hline & Female & 63 & 25.3 & 33 & 29.7 & 96 & 26.7 \\
\hline & Missing & 3 & 1.2 & 1 & 0.9 & 3 & 0.8 \\
\hline \multirow[t]{8}{*}{ Age (years) } & less than 20 & 22 & 8.8 & 15 & 13.5 & 39 & 10.8 \\
\hline & $20-25$ & 123 & 49.4 & 51 & 45.9 & 174 & 48.3 \\
\hline & $26-30$ & 53 & 21.3 & 22 & 19.8 & 75 & 20.8 \\
\hline & $31-35$ & 19 & 7.6 & 11 & 9.9 & 30 & 8.3 \\
\hline & $36-40$ & 12 & 4.8 & 5 & 4.5 & 17 & 4.7 \\
\hline & $41-50$ & 15 & 6.0 & 3 & 2.7 & 18 & 5.0 \\
\hline & older than 50 & 2 & 0.8 & 3 & 2.7 & 5 & 1.4 \\
\hline & Missing & 3 & 1.2 & 1 & 0.9 & 3 & 0.8 \\
\hline \multirow[t]{10}{*}{ Annual Salary } & Less than US $\$ 12,500$ & 67 & 26.9 & 55 & 49.5 & 122 & 33.9 \\
\hline & US $\$ 12,500$ - US $\$ 24,999$ & 45 & 18.1 & 26 & 23.4 & 71 & 19.7 \\
\hline & US $\$ 25,000$ - US $\$ 37,499$ & 35 & 14.1 & 8 & 7.2 & 43 & 11.9 \\
\hline & US $\$ 37,500$ - US $\$ 49,999$ & 37 & 14.9 & 5 & 4.5 & 42 & 11.7 \\
\hline & US $\$ 50,000$ - US $\$ 62,499$ & 23 & 9.2 & 5 & 4.5 & 28 & 7.8 \\
\hline & US $\$ 62,500$ - US $\$ 74,999$ & 13 & 5.2 & 2 & 1.8 & 15 & 4.2 \\
\hline & US $\$ 75,000$ - US $\$ 87,499$ & 10 & 4.0 & 4 & 3.6 & 14 & 3.9 \\
\hline & US $\$ 87,500$ - US $\$ 99,999$ & 7 & 2.8 & 4 & 3.6 & 11 & 3.1 \\
\hline & US $\$ 100,000$ or More & 6 & 2.4 & 0 & 0.0 & 6 & 1.7 \\
\hline & Prefer not to say & 5 & 2.0 & 1 & 0.9 & 6 & 1.7 \\
\hline \multirow[t]{6}{*}{ Duration of Prior Use } & Less than a month & 7 & 2.8 & 7 & 6.3 & 14 & 3.9 \\
\hline & Less than a year & 49 & 19.7 & 25 & 22.5 & 74 & 20.6 \\
\hline & One to two years & 76 & 30.5 & 17 & 15.3 & 93 & 25.8 \\
\hline & Two to three years & 47 & 18.9 & 18 & 16.2 & 65 & 18.1 \\
\hline & Three to four years & 28 & 11.2 & 15 & 13.5 & 43 & 11.9 \\
\hline & Four to five years & 18 & 7.2 & 9 & 8.1 & 27 & 7.5 \\
\hline
\end{tabular}




\begin{tabular}{|l|l|l|l|l|l|l|l|}
\hline & Five years or more & 20 & 8.0 & 18 & 16.2 & 38 & 10.6 \\
\hline
\end{tabular}

\subsection{Modelling}

We required a multivariate analysis technique to test the research model. We chose a Partial Least Squares (PLS) technique for the analysis, a popular multivariate technique in previous IS research (Gefen and Straub, 2005). PLS path techniques are robust to sample size and distributional non-normality (Fornell and Bookstein, 1982). The PLS technique comprises both a measurement model stage and a structural model stage. These two stages allow the researcher to gauge both the quality of measurement for each item and construct, and the quality of the relationships between constructs.

\subsubsection{Assessing the Measurement Model}

We first checked the data for missing values and outliers. Then, following the procedure outlined by Hair (2006), we evaluated the model's psychometric properties, by gauging convergent validity, discriminant validity and construct reliability. Convergent validity, the inter-item correlation (Campbell and Fiske, 1959), was evaluated by inspecting item loadings for each construct. Table 2 shows the results for each outer path in the model for both respondent groups, and the associated t-statistics for each item. All item loadings were significant at the .001 level. These results suggest acceptable convergent validity.

Table 2 Item Loadings for Reflective Constructs

\begin{tabular}{|c|c|c|c|c|c|c|}
\hline \multirow[t]{2}{*}{ Construct } & \multirow[t]{2}{*}{ Item label } & \multirow[t]{2}{*}{ Item } & \multicolumn{2}{|c|}{$\begin{array}{c}\text { High integration } \\
\text { users }\end{array}$} & \multicolumn{2}{|c|}{$\begin{array}{l}\text { Low } \\
\text { integration } \\
\text { users }\end{array}$} \\
\hline & & & Value & t-stat & Value & t-stat \\
\hline \multirow{3}{*}{$\begin{array}{l}\text { Problem- } \\
\text { Focused Coping }\end{array}$} & PROB1 & I would think about how I might best handle the problem. & 0.73 & 7.69 & 0.80 & 19.35 \\
\hline & PROB2 & I try to come up with a strategy about what to do. & 0.76 & 9.28 & 0.80 & 15.58 \\
\hline & PROB3 & $\begin{array}{l}\text { I would not think about what steps to take to resolve the } \\
\text { problem. * }\end{array}$ & 0.79 & 12.63 & 0.86 & 38.10 \\
\hline \multirow{3}{*}{$\begin{array}{l}\text { Emotion } \\
\text { Focused Coping }\end{array}$} & EMOC1 & I would try to keep my feelings to myself. & 0.84 & 16.25 & 0.74 & 12.19 \\
\hline & EMOC2 & I would try to show other people how I really felt. * & 0.62 & 5.41 & 0.87 & 33.17 \\
\hline & EMOC3 & I would try to hold back my feelings. & 0.85 & 19.46 & 0.86 & 25.98 \\
\hline Engagement & ENGA1 & $\begin{array}{l}\text { I would not let the cloud service company know how I am } \\
\text { feeling. * }\end{array}$ & 0.80 & 13.11 & 0.85 & 26.82 \\
\hline
\end{tabular}




\begin{tabular}{|l|l|l|l|l|l|l|}
\hline \multirow{5}{*}{} & ENGA2 & I present my point of view and argue my case. & 0.78 & 16.33 & 0.87 & 25.26 \\
\cline { 2 - 7 } & ENGA3 & $\begin{array}{l}\text { I talk to the cloud service provider to complain about the } \\
\text { situation. }\end{array}$ & 0.89 & 38.51 & 0.88 & 25.21 \\
\cline { 2 - 7 } & ENGA4 & $\begin{array}{l}\text { I tell the cloud service host about the problem and ask them } \\
\text { to correct it. }\end{array}$ & 0.85 & 23.58 & 0.86 & 25.99 \\
\cline { 2 - 7 } & ENGA5 & $\begin{array}{l}\text { I would not express my feelings to the cloud service } \\
\text { provider. * }\end{array}$ & 0.86 & 23.23 & 0.86 & 24.90 \\
\hline \multirow{3}{*}{ Disengagement } & DISE1 & I resign myself to the fact that further efforts are futile. & 0.84 & 21.93 & 0.80 & 13.92 \\
\cline { 2 - 7 } & DISE2 & I give up attempting to get what I wanted. & 0.81 & 15.56 & 0.81 & 15.72 \\
\cline { 2 - 7 } & DISE3 & I would just forget about the whole situation. & 0.82 & 14.40 & 0.78 & 11.74 \\
\hline * Indicates reverse & coded item & & &
\end{tabular}

We then examined discriminant validity, the discriminatory power of the items, by inspecting the degree to which items loaded higher onto their own construct than other constructs. Table 3 shows the item loadings to construct correlations and also the square root calculations of the Average Variance Extracted (AVE) (Gefen and Straub, 2005). these item loadings. All items load the greatest onto their respective constructs, shown in bold, indicating acceptable discriminant validity. Table 4 shows the square root of AVE values, which exceeded the other correlations (Fornell and Larcker, 1981). These results indicated acceptable discriminant validity.

Table 3 Item and Construct Cross Loadings

\begin{tabular}{|l|l|l|l|l|l|l|l|l|}
\hline & Problem-Focused Coping & \multicolumn{2}{l|}{ Emotion-Focused Coping } & \multicolumn{2}{l|}{ Engagement } & \multicolumn{2}{l|}{ Disengagement } \\
\hline & $\begin{array}{l}\text { High } \\
\text { integration } \\
\text { users }\end{array}$ & $\begin{array}{l}\text { Low } \\
\text { integration } \\
\text { users }\end{array}$ & $\begin{array}{l}\text { High } \\
\text { integration } \\
\text { users }\end{array}$ & $\begin{array}{l}\text { Low } \\
\text { integration } \\
\text { users }\end{array}$ & $\begin{array}{l}\text { High } \\
\text { integration } \\
\text { users }\end{array}$ & $\begin{array}{l}\text { Low } \\
\text { integration } \\
\text { users }\end{array}$ & $\begin{array}{l}\text { High } \\
\text { integration } \\
\text { users }\end{array}$ & $\begin{array}{l}\text { Low } \\
\text { integration } \\
\text { users }\end{array}$ \\
\hline PROB1 & $\mathbf{0 . 7 3}$ & $\mathbf{0 . 8 0}$ & 0.25 & 0.42 & -0.40 & -0.34 & 0.21 & 0.41 \\
\hline PROB2 & $\mathbf{0 . 7 6}$ & $\mathbf{0 . 8 0}$ & 0.25 & 0.40 & -0.38 & -0.37 & 0.16 & 0.51 \\
\hline PROB3 & $\mathbf{0 . 7 9}$ & $\mathbf{0 . 8 6}$ & 0.34 & 0.58 & -0.48 & -0.48 & 0.43 & 0.63 \\
\hline EMOC1 & 0.26 & 0.29 & $\mathbf{0 . 8 4}$ & $\mathbf{0 . 7 4}$ & -0.48 & -0.52 & 0.46 & 0.27 \\
\hline EMOC2 & 0.34 & 0.60 & $\mathbf{0 . 6 2}$ & $\mathbf{0 . 8 7}$ & -0.60 & -0.75 & 0.03 & 0.46 \\
\hline EMOC3 & 0.30 & 0.49 & $\mathbf{0 . 8 5}$ & $\mathbf{0 . 8 6}$ & -0.51 & -0.64 & 0.52 & 0.62 \\
\hline ENGA1 & -0.42 & -0.39 & -0.58 & -0.70 & $\mathbf{0 . 8 0}$ & $\mathbf{0 . 8 5}$ & -0.41 & -0.34 \\
\hline ENGA2 & -0.49 & -0.43 & -0.53 & -0.64 & $\mathbf{0 . 7 8}$ & $\mathbf{0 . 8 7}$ & -0.13 & -0.35 \\
\hline ENGA3 & -0.45 & -0.46 & -0.57 & -0.66 & $\mathbf{0 . 8 9}$ & $\mathbf{0 . 8 8}$ & -0.32 & -0.37 \\
\hline ENGA4 & -0.50 & -0.46 & -0.49 & -0.68 & $\mathbf{0 . 8 5}$ & $\mathbf{0 . 8 6}$ & -0.30 & -0.34 \\
\hline ENGA5 & -0.47 & -0.37 & -0.63 & -0.69 & $\mathbf{0 . 8 6}$ & $\mathbf{0 . 8 6}$ & -0.44 & -0.39 \\
\hline DISE1 & 0.33 & 0.49 & 0.40 & 0.41 & -0.35 & -0.34 & $\mathbf{0 . 8 4}$ & $\mathbf{0 . 8 0}$ \\
\hline DISE2 & 0.34 & 0.57 & 0.32 & 0.41 & -0.24 & -0.25 & $\mathbf{0 . 8 1}$ & $\mathbf{0 . 8 1}$ \\
\hline
\end{tabular}




\begin{tabular}{|l|l|l|l|l|l|l|l|l|}
\hline DISE3 & 0.27 & 0.47 & 0.43 & 0.53 & -0.35 & -0.41 & $\mathbf{0 . 8 2}$ & $\mathbf{0 . 7 8}$ \\
\hline
\end{tabular}

Table 4 Latent Variable Correlations and Square Root of Average Variance Extracted (AVE)

\begin{tabular}{|l|l|l|l|l|l|}
\hline & & Disengagement & Emotion-Focused & Engagement & Problem-Focused \\
\hline \multirow{4}{*}{$\begin{array}{l}\text { High integration } \\
\text { users }\end{array}$} & Disengagement & 0.78 & & & \\
\cline { 2 - 6 } & Emotion-Focused & 0.47 & 0.78 & & \\
\cline { 2 - 6 } & Engagement & -0.38 & -0.67 & 0.79 & 0.76 \\
\cline { 2 - 6 } & Problem-Focused & -0.38 & -0.38 & 0.56 & \\
\hline \multirow{4}{*}{$\begin{array}{l}\text { Low integration } \\
\text { users }\end{array}$} & & & & & \\
\cline { 2 - 6 } & Eisengagement & 0.76 & 0.79 & & \\
\cline { 2 - 6 } & Enotion-Focused & 0.57 & -0.78 & 0.80 & \\
\hline & Engagement & -0.42 & -0.58 & 0.49 & \\
\hline
\end{tabular}

Reliability describes the degree of internal construct consistency. Table 5 shows the results of the composite reliability, Cronbach Alpha and Average Variance Extracted (AVE) for each construct. Composite reliability exceeded the threshold of 0.7 (Hair et al., 2006). AVE values were above the threshold of 0.5 (Anderson and Gerbing, 1988). These results revealed acceptable construct reliability.

Table 5 Composite Reliability, Average Variance Extracted (AVE) and $R^{2}$ Values

\begin{tabular}{|l|l|l|l|l|l|l|l|l|}
\hline & \multicolumn{2}{|c|}{ AVE } & \multicolumn{2}{c|}{ Composite Reliability } & \multicolumn{2}{c|}{$\mathrm{R}^{2}$} & \multicolumn{2}{c|}{ Cronbach Alpha } \\
\hline & $\begin{array}{l}\text { High } \\
\text { integration } \\
\text { users }\end{array}$ & $\begin{array}{l}\text { Low } \\
\text { integration } \\
\text { users }\end{array}$ & $\begin{array}{l}\text { High } \\
\text { integration } \\
\text { users }\end{array}$ & $\begin{array}{l}\text { Low } \\
\text { integration } \\
\text { users }\end{array}$ & $\begin{array}{l}\text { High } \\
\text { integration } \\
\text { users }\end{array}$ & $\begin{array}{l}\text { Low } \\
\text { integration } \\
\text { users }\end{array}$ & $\begin{array}{l}\text { High } \\
\text { integration } \\
\text { users }\end{array}$ & $\begin{array}{l}\text { Low } \\
\text { integration } \\
\text { users }\end{array}$ \\
\hline Disengagement & 0.68 & 0.64 & 0.86 & 0.84 & 0.27 & 0.47 & 0.76 & 0.71 \\
\hline Emotion-Focused & 0.60 & 0.68 & 0.82 & 0.87 & & & 0.66 & 0.77 \\
\hline Engagement & 0.70 & 0.74 & 0.92 & 0.94 & 0.56 & 0.61 & 0.89 & 0.91 \\
\hline Problem-Focused & 0.58 & 0.68 & 0.80 & 0.86 & & & 0.65 & 0.77 \\
\hline
\end{tabular}

\subsubsection{Assessing the Structural Model}

In the next stage, we assessed the model's structural properties by inspecting the path coefficients and construct $\mathrm{R}^{2}$ values. Table 6 shows the results of the path variance testing, 
the model path coefficients and their respective t-statistics. Figure 2 shows the path coefficients for the model, all but one of which were significant at the $\mathrm{p}<.001$ threshold.

Table 7 shows the testing outcomes of each main research hypothesis.

Table 6 Structural Model Path Coefficients and Main Hypothesis Results

\begin{tabular}{|c|l|l|l|l|l|l|}
\hline \multirow{2}{*}{ Hypothesis } & \multirow{2}{*}{ Path } & \multicolumn{2}{l|}{ High integration users } & \multicolumn{2}{l|}{ Low integration users } & Variance \\
\cline { 3 - 8 } & & Coefficient & t-statistic & Coefficient & t-statistic & Significance \\
\hline $\mathrm{H} 1 \mathrm{a}$ & Problem-Focused -> Engagement & 0.36 & $4.09^{* * *}$ & 0.06 & $0.63(\mathrm{NS})$ & $0.02^{*}$ \\
\hline $\mathrm{H} 2 \mathrm{a}$ & Problem-Focused -> Disengagement & -0.24 & $2.00^{* *}$ & -0.47 & $5.74^{* * *}$ & $0.05^{*}$ \\
\hline $\mathrm{H} 3 \mathrm{a}$ & Emotion-Focused -> Engagement & -0.54 & $6.64^{* * *}$ & -0.75 & $11.82^{* * *}$ & $0.02^{*}$ \\
\hline $\mathrm{H} 4 \mathrm{a}$ & Emotion-Focused -> Disengagement & 0.38 & $3.10^{* * *}$ & 0.30 & $3.16^{* * *}$ & $0.31(\mathrm{NS})$ \\
\hline${ }^{* * *}: \mathrm{p}<0.001 ;{ }^{* *}: \mathrm{p}<0.01 ;{ }^{*}: \mathrm{p}<0.05$ & & & & \\
\hline
\end{tabular}

Figure 2 Structural Model of Coping and Engagement Response

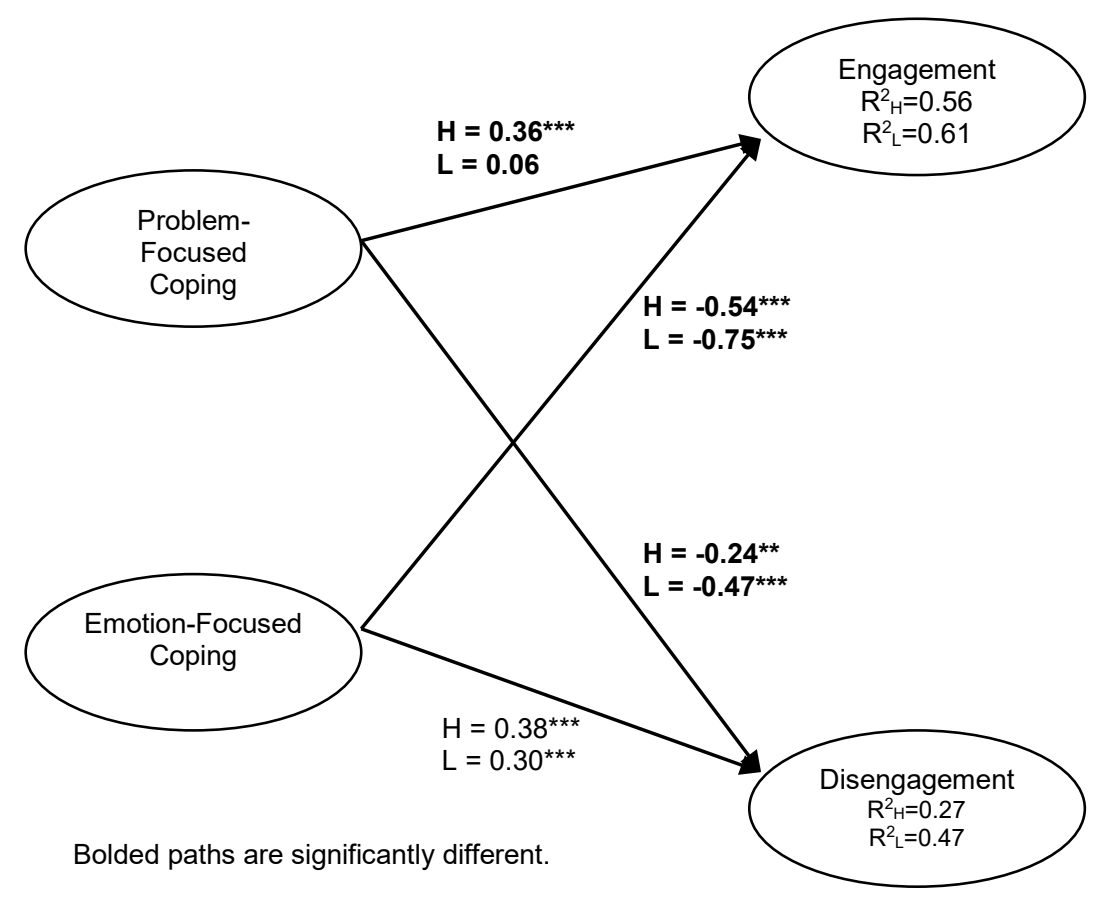

Table 7 Research Hypotheses and Testing Outcomes

\begin{tabular}{|c|l|l|}
\hline Hypothesis & Statement & Outcome \\
\hline $\mathrm{H} 1 \mathrm{a}$ & There is a positive relationship between problem-focused coping and engagement & Not Accepted \\
\hline
\end{tabular}




\begin{tabular}{|c|l|l|}
\hline $\mathrm{H} 1 \mathrm{~b}$ & $\begin{array}{l}\text { The relationship between problem-focused coping and engagement will be greater for } \\
\text { high-integration users than low-integration users. }\end{array}$ & Accepted \\
\hline $\mathrm{H} 2 \mathrm{a}$ & There is a negative relationship between emotion-focused coping and disengagement & Accepted \\
\hline $\mathrm{H} 2 \mathrm{~b}$ & $\begin{array}{l}\text { The relationship between problem-focused coping and disengagement will be lower for } \\
\text { high-integration users than low-integration users. }\end{array}$ & Accepted \\
\hline $\mathrm{H} 3 \mathrm{a}$ & There is a negative relationship between emotion-focused coping and engagement & Accepted \\
\hline $\mathrm{H} 3 \mathrm{~b}$ & $\begin{array}{l}\text { The relationship between emotion-focused coping and engagement will be lower for } \\
\text { high-integration users than low-integration users. }\end{array}$ & Accepted \\
\hline $\mathrm{H} 4 \mathrm{a}$ & There is a positive relationship between emotion-focused coping and disengagement. & Accepted \\
\hline $\mathrm{H} 4 \mathrm{~b}$ & $\begin{array}{l}\text { The relationship between emotion-focused coping and disengagement will be lower for } \\
\text { high-integration users than low-integration users. }\end{array}$ & Not Accepted \\
\hline
\end{tabular}

\section{Discussion}

We began this study in order to better understand how two main coping mechanisms affected the user's propensity to engage with a provider (by confronting or questioning about the service) or to disengage (and attempt to solve the problem using their own reasoning and adaptation). Broadly, we found that problem-focused coping was negatively related to disengagement and positively related to engagement. We also found that emotional coping mechanisms were negatively related to engagement for both kinds of users. Our particular findings are as follows.

First, we found a positive relationship between problem-focused coping and engagement for high integration users. However, we found no relationship between problem-focused coping and engagement for low integration users $\left(\beta_{\mathrm{H}}=0.36, \mathrm{p}<.001 ; \beta_{\mathrm{L}}=0.06, \mathrm{NS}\right)$. Hence, we did not accept hypothesis H1a. We found a stronger relationship between these two constructs for high integration users and therefore we accepted hypothesis H1b. High integration users, who are likely to be more functionally attached to their cloud storage services, are more likely to reason through the problem, leading to searching out a solution with the service provider. By contrast, low integration users do not necessarily display this behavior.

The results showed a significant negative relationship between problem-focused coping and disengagement behaviors for both user groups $\left(\beta_{\mathrm{H}}=-0.24, \mathrm{p}<.01 ; \beta_{\mathrm{L}}=-0.47, \mathrm{p}<.001\right)$. 
Therefore, we accepted hypothesis $\mathrm{H} 2 \mathrm{a}$. As a user considers the problem and attempts to cognitively weigh its effects and causes, they are less likely to disengage from the problem. We observed this relationship for both user groups, suggesting that the degree of functional attachment does not on its own allow users to disengage. However, we saw a significant more negative relationship for low integration users than high integration users for these constructs and hence we accepted hypothesis H2b. In other words, users who use more than one cloud service are more likely to give up on solving the problem when they attempt to cognitively work on the problem. This would make sense, because a low level of functional attachment might also mean that the user could simply switch to another cloud provider if the problem becomes too great. Conducting mental work on the problem could also become too great a cognitive burden, which users might prefer to avoid. As a result, significant problem-focused coping is more likely to result in disengagement for low integration users than for high integration users.

The analysis showed a significant negative relationship between emotion-focused coping and engagement for both groups of users $\left(\beta_{\mathrm{H}}=-0.54, \mathrm{p}<.001 ; \beta_{\mathrm{L}}=-0.75, \mathrm{p}<.001\right)$. We predicted this finding and hence we accepted hypothesis H3a. This finding reinforces the contention that emotion-focused coping constitutes an emotional burden on the user. The user wants to minimize this emotional strife and works to minimize it. However, the separation between the user and the cloud service means that the problem can feel emotionally unresolved. Engaging with the service provider allows them to resolve the dissonance and discomfort, bringing closure to the problem. When the user focuses on their emotions, they are less likely to want to commiserate with other parties who they feel might not sympathize with their plight. However, we also observed a stronger negative relationship between these two constructs for the low integration group and we accepted hypothesis H3b. While both groups displayed negative reactions, it was significantly stronger for the low integration 
group. This indicates that even though both groups are unlikely to engage with and confront with the service provider, high integration users, with higher functional attachment, are less likely to avoid this engagement.

The results showed a positive relationship between emotion-focused coping and disengagement $\left(\beta_{\mathrm{H}}=-0.38, \mathrm{p}<.001 ; \beta_{\mathrm{L}}=-0.30, \mathrm{p}<.001\right)$ and we accepted hypothesis H4a. The finding suggests that emotion-focused coping is more likely to result in a reclusion and emotional submission. However, we did not see a significant difference between the two groups for these constructs, and therefore we did not accept hypothesis H4b.

\section{Conclusions}

We contrasted two types of user in this study, being high integration and low integration users. We found that these user types cope with online service loss in different ways. High integration users were more likely to cope using problem-solving, and to engage with the provider rather than disengage. However, overall, low integration users were more emotionbased, and they engagement displayed by these users was more strongly emotion-dependent. These users were also more likely to disengage, both cognitively and emotionally. We find that when a user chooses to cope by managing their emotions, they are less likely to engage with and confront the service provider. However, they are then also more likely to disengage from the problem. We also find that when a user copes by working to solve the problem they are less likely to disengage and, for high integration users, more likely to engage with and confront the service provider.

The study raises several implications. First, we have shown that coping mechanisms may be affected by the degree of integration offered by the service provider. While integration is useful to the user (Liu et al., 2011), the loss of a highly integrated service is costly, consistent with Bygstad et al. (2010). Both high and low integration users could exhibit the same coping 
strategies, but with differing outcomes. Our findings suggest that when using coping through emotional means, high integration users are less likely not to engage than low integration users. When coping using a problem solving approach, high integration users are less likely not to disengage than low integration users. In sum, this finding could mean that low integration users are already expecting service failure of some kind and hence that are ready: should one occur, they may not engage, but they also may not disengage. By contrast, a high integration user may have a significant amount of investment in their service use, with more to lose in the event of failure: if the service should fail, they may engage with the provider, but they may also disengage. For these high integration users, the shock of service failure could be much greater and hence they are more sensitive to disruption. High integration service users don't simply have more to lose: they may also demonstrate more extreme reactions to service loss.

Next, prior work has argued that switching occurs as a result of service quality concerns (c.f. Keaveney and Parthasarathy, 2001; Kim et al., 2006). Our work suggests that coping mechanisms may play a role in switching outcomes. If a user is unable to cope with service failure, they will disengage from use. This disengagement could allow them to leave the provider, in search of another. Such switching behavior, in turn, may also make their coping mechanisms easier to manage, consistent with Heppner et al. (1995). Low integration users may not need to work to solve the problem because they can switch to another provider as they wish. Instead, they can allow their emotions to constitute the bulk of their coping reactions: as a result, the user may switch even if they know that other providers are inferior (Shiv and Fedorikhin, 1999). If they feel sufficiently emotional about the service loss, they may "rebound" to another provider even if the potential costs of this provider are greater than the incumbent. An important implication of this finding is that the degree of potential 
involvement and investment in the service affects the way in which the service user copes with service failure.

A third implication is that cloud service services should not necessarily be treated as a homogenous group. There are numerous types of cloud storage available, and the variety of services has implications for the users that patronize these service providers. Evidence in our study has shown that users cope with the loss of the service depending on the level of service integration - however, they may also differ along other dimensions, such as use intentions, habitual continuance and perceived usefulness (Zhang and McDowell, 2009). Fundamentally, our evidence suggests that these cloud services are not always interchangeable and treating them as such may be erroneous.

Practically, there is evidence that engagement is likely to be more emotive for high integration users: high integration users are more likely engage than low integration users when using problem-focused coping, and less likely not to engage when using emotionfocused coping. Providers may be able to predict the degree of emotive response by determining the degree of integration of the services used by their user base. High integration users are more likely to engage from a cognitive perspective, whereas engagement for low integration users appears to be almost wholly emotional. Low integration users also appear slightly more likely to disengage. Therefore, determining user integration may assist the service provider in understanding this disengagement and boosting customer retention. In addition, our results suggest that engagement and disengagement are not necessarily mirrors of each other.

The study may be open to a number of limitations. First, the legal upheaval surrounding some cloud storage providers may dissuade users from accurately or honestly reporting their use of these services: this potential reluctance ought to be borne in mind when evaluating user 
propensities. We also surveyed current cloud users, as a prerequisite to study participation.

Users who had discontinued their use may exhibit different coping characteristics to those covered in this study. Numerous cloud storage services exist. We selected 17 popular providers. Analyses involving different providers may yield different outcomes.

There are a number of areas for future research. We presented evidence that some low integration users might be more likely to disengage as a coping outcome. It would be interesting to see whether coping outcomes could be changed by improving the level of integration experienced by the user. For example, it might be interesting to examine whether users engaged more when a mobile application was released in concert with a service website or desktop application. Similarly, it might be interesting to see whether the amount of information available to the user affected their coping strategy. Specifically, it would be useful to determine whether enhancing or constricting the amount of information moved users towards or away from problem-based coping mechanisms.

\section{References}

Abel, D.J., Kilby, P.J., Davis, J.R., 1994. The systems integration problem. International Journal of Geographical Information Systems 8, 1-12.

Aerts, A.T.M., Goossenaerts, J.B.M., Hammer, D.K., Wortmann, J.C., 2004. Architectures in context: on the evolution of business, application software, and ICT platform architectures. Information \& Management 41, 781-794.

Ajzen, I., 1991. The theory of planned behavior. Organizational Behavior and Human Decision Processes 50, 179-211.

Ajzen, I., 2002. Perceived behavioral control, self-efficacy, locus of control, and the theory of planned behavior. Journal of Applied Social Psychology 32, 665-683.

Anderson, J.M., Gerbing, D., 1988. Structural equation modeling in practice: a review and recommended two-step approach. Psychological Bulletin 103, 411-423.

Avison, D., Jones, J., Powell, P., Wilson, D., 2004. Using and validating the strategic alignment model. The Journal of Strategic Information Systems 13, 223-246.

Baker, J.P., Berenbaum, H., 2007. Emotional approach and problem-focused coping: A comparison of potentially adaptive strategies. Cognition \& Emotion 21, 95-118.

Barki, H., Pinsonneault, A., 2005. A Model of Organizational Integration, Implementation Effort, and Performance. Organization Science 16, 165-179.

Beaudry, A., Pinsonneault, A., 2005. Understanding User Responses to Information Technology: A Coping Model of User Adaptation. MIS Quarterly 29, 493-524. 
Beaudry, A., Pinsonneault, A., 2010. The other side of acceptance: studying the direct and indirect effects of emotions on information technology use. MIS Quarterly 34, 689710.

Benamati, J., Lederer, A.L., 2001. Rapid Information Technology Change, Coping Mechanisms, and the Emerging Technologies Group. Journal of Management Information Systems 17, 183-202.

Bergeron, F., Raymond, L., 1992. The advantages of electronic data interchange. Database for Advances in Information Systems 23, 19-31.

Bhandari, M.S., Tsarenko, Y., Polonsky, M.J., 2007. A proposed multi-dimensional approach to evaluating service recovery. Journal of Services Marketing 21, 174-185.

Billings, A.G., Moos, R.H., 1981. The role of coping responses and social resources in attenuating the stress of life events. Journal of Behavioral Medicine 4, 139-157.

Boudreau, M.-C., Robey, D., 1996. Coping with contradictions in business process reengineering. Information Technology \& People 9, 40-57.

Brey, P., 2005. Freedom and Privacy in Ambient Intelligence. Ethics and Information Technology 7, 157-166.

Bygstad, B., Nielsen, P.A., Munkvold, B.E., 2010. Four integration patterns: a sociotechnical approach to integration in IS development projects. Information Systems Journal 20, 53-80.

Campbell, D.T., Fiske, D.W., 1959. Convergent and discriminant validation by the multitraitmultimethod matrix. Psychological Bulletin 56, 81-105.

Cappiello, C., Francalanci, C., Pernici, B., 2003. Time-Related Factors of Data Quality in Multichannel Information Systems. Journal of Management Information Systems 20, 71-92.

Carver, C.S., Connor-Smith, J., 2010. Personality and Coping. Annual Review of Psychology 61, 679-704.

Carver, C.S., Scheier, M.F., 1994. Situational coping and coping dispositions in a stressful transaction. Journal of Personality and Social Psychology 66, 184-195.

Carver, C.S., Scheier, M.F., Weintraub, J.K., 1989. Assessing coping strategies: A theoretically based approach. Journal of Personality and Social Psychology 56, 267 283.

Cazier, J., Jensen, A., Dave, D., 2008. The Impact of Consumer Perceptions of Information Privacy and Security Risks on the Adoption of Residual RFID Technologies. Communications of the Association for Information Systems 23.

Charlton, J.P., Danforth, I.D.W., 2007. Distinguishing addiction and high engagement in the context of online game playing. Computers in Human Behavior 23, 1531-1548.

Chesney, T., Coyne, I., Logan, B., Madden, N., 2009. Griefing in virtual worlds: causes, casualties and coping strategies. Information Systems Journal 19, 525-548.

Collier, J.E., Bienstock, C.C., 2006. Measuring Service Quality in E-Retailing. Journal of Service Research 8, 260-275.

Compas, B.E., 1998. An Agenda for Coping Research and Theory: Basic and Applied Developmental Issues. International Journal of Behavioral Development 22, 231-237.

Constantinides, E., 2004. Influencing the online consumer's behavior: the Web experience. Internet Research 14, 111-126.

Cooper, D.R., Schindler, P.S., 2003. Business research methods, 8th ed. McGraw-Hill Irwin, Boston, MA.

Dillman, D.A., 1978. Mail and Telephone Surveys: The Total Design Method. Wiley Publishing, New York.

Dillman, D.A., Smyth, J.D., Christian, L.M., 2008. Internet, Mail, and Mixed-Mode Surveys: The Tailored Design Method, 3rd ed. Wiley Publishing. 
Dunkel-Schetter, C., Folkman, S., Lazarus, R.S., 1987. Correlates of social support receipt. Journal of Personality and Social Psychology 53, 71-80.

Elgarah, W., Falaleeva, N., Saunders, C.C., Ilie, V., Shim, J.T., Courtney, J.F., 2005. Data exchange in interorganizational relationships: review through multiple conceptual lenses. Database for Advances in Information Systems 36, 8-29.

Elliot, A.J., Thrash, T.M., 2002. Approach-avoidance motivation in personality: Approach and avoidance temperaments and goals. Journal of Personality and Social Psychology 82, 804-818.

Endler, N.S., Parker, J.D.A., 1990. Multidimensional assessment of coping: A critical evaluation. Journal of Personality and Social Psychology 58, 844-854.

Fishbein, M., Ajzen, I., 1975. Belief, attitude, intention, and behavior: an introduction to theory and research. Addison-Wesley Publishers, Reading, Mass.

Folkman, S., 2010. Stress, Health, and Coping: An Overview, in: Folkman, S., Nathan, P.E. (Eds.), The Oxford Handbook of Stress, Health, and Coping. Oxford University Press.

Folkman, S., Lazarus, R.S., 1980. An analysis of coping in a middle-aged community sample. Journal of Health and Social Behavior 21, 219-239.

Folkman, S., Lazarus, R.S., Dunkel-Schetter, C., DeLongis, A., Gruen, R.J., 1986. Dynamics of a stressful encounter: Cognitive appraisal, coping, and encounter outcomes. Journal of Personality and Social Psychology 50, 992-1003.

Folkman, S., Moskowitz, J.T., 2000. Positive affect and the other side of coping. American Psychologist 55, 647-654.

Folkman, S., Moskowitz, J.T., 2004. Coping: Pitfalls and Promise. Annual Review of Psychology 55, 745-774.

Fornell, C., Bookstein, F.L., 1982. Two Structural Equation Models: LISREL and PLS Applied to Consumer Exit-Voice Theory. Journal of Marketing Research 19, 440.

Fornell, C., Larcker, D.F., 1981. Evaluating Structural Equation Models with Unobservable Variables and Measurement Error. Journal of Marketing Research 18, 39-50.

Forsythe, C.J., Compas, B.E., 1987. Interaction of cognitive appraisals of stressful events and coping: Testing the goodness of fit hypothesis. Cognitive Therapy Research 11, 473485.

Francalanci, C., Morabito, V., 2008. IS integration and business performance: The mediation effect of organizational absorptive capacity in SMEs. Journal of Information Technology 23, 297-312.

Fredrickson, B.L., Branigan, C., 2003. Positive emotions broaden the scope of attention and thought-action repertoires. Cognition \& Emotion 19, 313-332.

Galliers, R.D., 1992. Choosing Information Systems Research Approaches, in: Galliers, R.D. (Ed.), Information Systems Research: Issues, Methods and Practical Guidelines. Blackwell Scientific, Oxford.

Gartner Research, 2010. Magic Quadrant for Cloud Infrastructure as a Service and Web Hosting. Gartner Inc., Cambridge, MA.

Gefen, D., Straub, D.W., 2005. A Practical Guide to Factorial Validity Using PLS-Graph: Tutorial and Annotated Example. Communications of the AIS 16, 91-109.

Gelbrich, K., 2010. Anger, frustration, and helplessness after service failure: coping strategies and effective informational support. Journal of the Academy of Marketing Science 38, $567-585$.

Goodhue, D.L., Wybo, M.D., Kirsch, L.J., 1992. The Impact of Data Integration on the Costs and Benefits of Information Systems. MIS Quarterly 16, 293-311.

Grover, V., Lee, C., Durand, D., 1993. Analysing Methodological Rigor of MIS Survey Research from 1980-1989. Information \& Management 24, 305-317. 
Hair, J.F., Black, W.C., Babin, B.J., Anderson, R.E., Tatham, R.L., 2006. Multivariate Data Analysis. Pearson Publishers, Upper Saddle River, NJ.

Harris, K.E., Mohr, L.A., Bernhardt, K.L., 2006. Online service failure, consumer attributions and expectations. Journal of Services Marketing 20, 453-458.

Heppner, P.P., Cook, S.W., Wright, D.M., Johnson, W.C., 1995. Progress in resolving problems: A problem-focused style of coping. Journal of Counseling Psychology 42, 279-293.

Hess, R.L., Ganesan, S., Klein, N.M., 2003. Service Failure and Recovery: The Impact of Relationship Factors on Customer Satisfaction. Journal of the Academy of Marketing Science 31, 127-145.

Holloway, B.B., Beatty, S.E., 2003. Service Failure in Online Retailing A Recovery Opportunity. Journal of Service Research 6, 92-105.

Holloway, B.B., Beatty, S.E., 2008. Satisfiers and Dissatisfiers in the Online Environment A Critical Incident Assessment. Journal of Service Research 10, 347-364.

Hong, R.Y., 2007. Worry and rumination: Differential associations with anxious and depressive symptoms and coping behavior. Behaviour Research and Therapy 45, $277-$ 290.

Irani, Z., Themistocleous, M., Love, P.E.D., 2003. The impact of enterprise application integration on information system lifecycles. Information \& Management 41, $177-$ 187.

Kammeyer-Mueller, J.D., Judge, T.A., Scott, B.A., 2009. The role of core self-evaluations in the coping process. Journal of Applied Psychology 94, 177-195.

Kashdan, T.B., Barrios, V., Forsyth, J.P., Steger, M.F., 2006. Experiential avoidance as a generalized psychological vulnerability: Comparisons with coping and emotion regulation strategies. Behaviour Research and Therapy 44, 1301-1320.

Keaveney, S.M., Parthasarathy, M., 2001. Customer switching behavior in online services: An exploratory study of the role of selected attitudinal, behavioral, and demographic factors. Journal of the Academy of Marketing Science 29, 374-390.

Keh, H.T., Pang, J., 2010. Customer Reactions to Service Separation. Journal of Marketing $74,55-70$.

Kim, G., Shin, B., Lee, H.G., 2006. A study of factors that affect user intentions toward email service switching. Information \& Management 43, 884-893.

Kuo, Y.-F., Wu, C.-M., 2012. Satisfaction and post-purchase intentions with service recovery of online shopping websites: Perspectives on perceived justice and emotions. International Journal of Information Management 32, 127-138.

Kuo, Y.-F., Yen, S.-T., Chen, L.-H., 2011. Online auction service failures in Taiwan: Typologies and recovery strategies. Electronic Commerce Research and Applications 10, 183-193.

Lam, W., 2005. Investigating success factors in enterprise application integration: a casedriven analysis. European Journal of Information Systems 14, 175-187.

Lazarus, R.S., Folkman, S., 1984. Stress, Appraisal, and Coping. Springer Publishing Company.

Lin, T., Hsu, J.S., Cheng, K., Wu, S., 2012. Understanding the role of behavioural integration in ISD teams: an extension of transactive memory systems concept. Information Systems Journal forthcoming.

Liu, L., Feng, Y., Hu, Q., Huang, X., 2011. From transactional user to VIP: how organizational and cognitive factors affect ERP assimilation at individual level. European Journal of Information Systems 20, 186-200. 
Major, B., Schmader, T., 1998. Coping with stigma through psychological disengagement, in: Prejudice: The Target's Perspective. Academic Press, San Diego, CA, US, pp. 219241.

Malhotra, R., Temponi, C., 2010. Critical decisions for ERP integration: Small business issues. International Journal of Information Management 30, 28-37.

March, S.T., Hevner, A.R., 2007. Integrated decision support systems: A data warehousing perspective. Decision Support Systems 43, 1031-1043.

Markus, M.L., 2000. Paradigm Shifts - E-Business and Business/Systems Integration. Communications of the Association for Information Systems 4.

Menon, K., Dubé, L., 2007. The effect of emotional provider support on angry versus anxious consumers. International Journal of Research in Marketing 24, 268-275.

Miller, C.T., Kaiser, C.R., 2001. A Theoretical Perspective on Coping With Stigma. Journal of Social Issues 57, 73-92.

Morash, E., Clinton, S., 1998. Supply chain integration: customer value through collaborative closeness versus operational excellence $6,104-120$.

Moynihan, T., 2002. Coping with client-based "people-problems": the theories-of-action of experienced IS/software project managers. Information \& Management 39, 377-390.

Narayanan, S., Marucheck, A.S., Handfield, R.B., 2009. Electronic Data Interchange: Research Review and Future Directions*. Decision Sciences 40, 121-163.

Nes, L.S., Segerstrom, S.C., 2006. Dispositional Optimism and Coping: A Meta-Analytic Review. Pers Soc Psychol Rev 10, 235-251.

Nicolaou, A.I., 2000. A contingency model of perceived effectiveness in accounting information systems: Organizational coordination and control effects. International Journal of Accounting Information Systems 1, 91-105.

Nilsson, E.G., Nordhagen, E.K., Oftedal, G., 1990. Aspects of systems integration, in: Proceedings of the First International Conference on Systems Integration. pp. 434 443.

Nunally, J.C., 1967. Psychometric Theory. McGraw-Hill Publishing Co.

Ofcom, 2010. Strategic review of consumer switching. Ofcom, London, UK.

Orlikowski, W.J., 1993. CASE tools as organizational change: investigating incremental and radical changes in systems development. MIS Quarterly 17, 309-340.

Palvia, P., Mao, E., Salam, A.F., Soliman, K.S., 2003. Management information systems research: what's there in a methodology. Communications of the AIS 11, 289-309.

Patterson, G.T., 2002. Development of a Law Enforcement Stress and Coping Questionnaire. Psychological Reports 90, 789-799.

Pearlin, L.I., Schooler, C., 1978. The Structure of Coping. Journal of Health and Social Behavior 19, 2-21.

Ren, Y., Kiesler, S., Fussell, S., 2008. Multiple Group Coordination in Complex and Dynamic Task Environments: Interruptions, Coping Mechanisms, and Technology Recommendations. Journal of Management Information Systems 25, 105-130.

Russell, D., 1982. The Causal Dimension Scale: A measure of how individuals perceive causes. Journal of Personality and Social Psychology 42, 1137-1145.

Savolainen, R., 2007. Filtering and Withdrawing: Strategies for Coping with Information Overload in Everyday Contexts. Journal of Information Science 33, 611-621.

Scheier, M.F., Weintraub, J.K., Carver, C.S., 1986. Coping with stress: Divergent strategies of optimists and pessimists. Journal of Personality and Social Psychology 51, 12571264.

Shiloh, S., Orgler-Shoob, M., 2006. Monitoring: A Dual-Function Coping Style. Journal of Personality 74, 457-478. 
Shiv, B., Fedorikhin, A., 1999. Heart and Mind in Conflict: The Interplay of Affect and Cognition in Consumer Decision Making. Journal of Consumer Research 26, 278292.

Straub, D.W., 1989. Validating Instruments in MIS Research. MIS Quarterly 13, 147-169.

Straub, D.W., Welke, R.J., 1998. Coping with Systems Risk: Security Planning Models for Management Decision Making. MIS Quarterly 22, 441-469.

Taha, L.H., Caldwell, B.S., 1993. Social isolation and integration in electronic environments. Behaviour \& Information Technology 12, 276-283.

Thoits, P.A., 1986. Social support as coping assistance. Journal of Consulting and Clinical Psychology 54, 416-423.

Tobin, D.L., Holroyd, K.A., Reynolds, R.V., Wigal, J.K., 1989. The hierarchical factor structure of the Coping Strategies Inventory. Cognitive Therapy and Research 13, 343-361.

Truman, G.E., 2000. Integration in Electronic Exchange Environments. Journal of Management Information Systems 17, 209-244.

Vatanasombut, B., Stylianou, A.C., Igbaria, M., 2004. How to retain online customers. Communications of the ACM 47, 64-70.

Vázquez-Casielles, R., del Río-Lanza, A., Díaz-Martín, A., 2007. Quality of past performance: Impact on consumers' responses to service failure. Marketing Letters $18,249-264$.

Wainwright, D., Waring, T., 2004. Three domains for implementing integrated information systems: redressing the balance between technology, strategic and organisational analysis. International Journal of Information Management 24, 329-346.

Wang, Y.-S., Wu, S.-C., Lin, H.-H., Wang, Y.-Y., 2011. The relationship of service failure severity, service recovery justice and perceived switching costs with customer loyalty in the context of e-tailing. International Journal of Information Management 31, 350359.

Weber, Y., Pliskin, N., 1996. The effects of information systems integration and organizational culture on a firm's effectiveness. Information \& Management 30, 8190.

Weinstein, N., Brown, K.W., Ryan, R.M., 2009. A multi-method examination of the effects of mindfulness on stress attribution, coping, and emotional well-being. Journal of Research in Personality 43, 374-385.

Wijnhoven, F., Spil, T., Stegwee, R., Fa, R.T.A., 2006. Post-merger IT integration strategies: An IT alignment perspective. The Journal of Strategic Information Systems 15, 5-28.

Wu, C., Lo, Y.H., 2012. Customer reactions to encountering consecutive service failures. Journal of Consumer Behaviour forthcoming.

Yi, S., Baumgartner, H., 2004. Coping With Negative Emotions in Purchase-Related Situations. Journal of Consumer Psychology 14, 303-317.

Zhang, L., McDowell, W.C., 2009. Am I Really at Risk? Determinants of Online Users' Intentions to Use Strong Passwords. Journal of Internet Commerce 8, 180-197. 


\section{Appendix: Coding of Integration of Cloud Storage Providers}

Our conceptualization of integration reflected the degree to which the cloud service allowed a user to incorporate the storage services into daily activities, and the degree of investment required in this act. Our aim was to classify our cloud storage service providers in terms of the level of integration that they afforded to users. We used a subjective classification method to differentiate between "low integration", "medium integration" and "high integration" services. Low integration services did not offer access to alternative use mechanisms such as desktop and mobile applications. They also did not provide direct access to the user's files (in other words, a user could not access a document directly from their desktop or from within an application). Low integration services also imposed barriers to use, such as CAPTCHA text challenges or intrusive advertising mechanisms, on the grounds that these requirements would act as barriers to fluid use and interaction, and also did not integrate or interoperate with other software tools. By contrast, high integration services provided greater levels of interoperability with other activities and processes. For instance, these services afforded access from a variety of places, such as desktop applications and mobile devices. They also allowed the user to access the cloud storage service from within with other software applications. Use of these services typically required a username and password, with higher service levels requiring paid account subscriptions. Medium integration services were considered to be the services that fell between these two extreme groups.

We evaluated each service provider on the basis of six criteria, as follows. First, direct file access referred to the ability for users to access their files directly and without any additional steps. Direct file access would allow the user to access the file as if it were still sitting on their desktop or within a folder on their computer. Second, the existence of an API (Application Protocol Interface) reflected the ease with which the cloud's services could be directly and seamlessly used from within other applications. An API would allow developers 
to design new applications based on the provider's services, for subsequent use on mobile devices. A provider without an API would require users to access their services solely through the website interface. Third, the availability of a desktop client would allow users to install and operate a piece of dedicated software for accessing their files and monitoring the provider's services. The availability of this dedicated software was seen to increase the level of integration by increasing the level of personal and functional investment in the provider's services. This desktop client was included regardless of operating system (e.g. Windows, Linux or Mac OS). Fourth, the availability of a mobile application also signaled greater integration with alternative access devices. Some providers offered mobile access support through their website in the form of an HTML5 page, and these were excluded from this count. The fifth factor was the availability of direct application integration. This factor included direct integration with other software tools that were not directly focused on file storage, such as Microsoft Word and Microsoft Outlook. The sixth factor was Account requirement, which reflected whether the service provider allowed for completely anonymous file hosting.

We categorized 17 popular cloud storages services using these criteria. Table 8 contains the results of this categorization process. We took the linear sum of these feature indicators to generate the final categorization. In cases where services sat at the margin, we excluded them from the ensuing analysis.

Table 8 Categorization of Cloud Storage Providers

\begin{tabular}{|l|l|l|l|l|l|l|l|}
\hline Provider & $\begin{array}{l}\text { Direct File } \\
\text { Access }\end{array}$ & API & $\begin{array}{l}\text { Desktop } \\
\text { client }\end{array}$ & $\begin{array}{l}\text { Mobile } \\
\text { client }\end{array}$ & $\begin{array}{l}\text { Application } \\
\text { integration }\end{array}$ & $\begin{array}{l}\text { Account } \\
\text { requirement }\end{array}$ & $\begin{array}{l}\text { Integration } \\
\text { Classification }\end{array}$ \\
\hline Box.net & 1 & 1 & 1 & 1 & 1 & 1 & High \\
\hline Dropbox & 1 & 1 & 1 & 1 & 1 & 1 & High \\
\hline Sugarsync & 1 & 1 & 1 & 1 & 1 & 1 & High \\
\hline 4Shared & 0 & 1 & 1 & 1 & 1 & 1 & Medium \\
\hline Sendspace & 0 & 1 & 1 & 1 & 0 & 0 & Medium \\
\hline YouSendlt & 0 & 1 & 1 & 1 & 1 & 1 & Medium \\
\hline
\end{tabular}




\begin{tabular}{|l|l|l|l|l|l|l|l|}
\hline Adrive & 0 & 1 & 1 & 0 & 1 & 1 & Medium \\
\hline Fileden & 1 & 0 & 0 & 0 & 0 & 1 & Low \\
\hline Filefactory & 0 & 0 & 0 & 0 & 0 & 0 & Low \\
\hline Fileserve & 0 & 0 & 0 & 0 & 0 & 1 & Low \\
\hline Hotfile & 0 & 0 & 0 & 0 & 0 & 0 & Low \\
\hline Mediafire & 1 & 0 & 1 & 0 & 0 & 1 & Low \\
\hline Netload & Delayed & 0 & 0 & 0 & 0 & 0 & Low \\
\hline Rapidshare & 0 & 1 & 1 & 0 & 0 & 1 & Low \\
\hline Uploaded.to & 0 & 0 & 0 & 0 & 0 & 1 & Low \\
\hline Uploading.com & 0 & 0 & 0 & 0 & 0 & 0 & Low \\
\hline Zshare & 0 & 0 & 0 & 0 & 0 & 0 & Low \\
\hline
\end{tabular}

Figure 3 shows the breakdown of service provider use between the high integration and low integration groups. 
Figure 3 Charts of Cloud Provider Use for High and Low Integration Groups

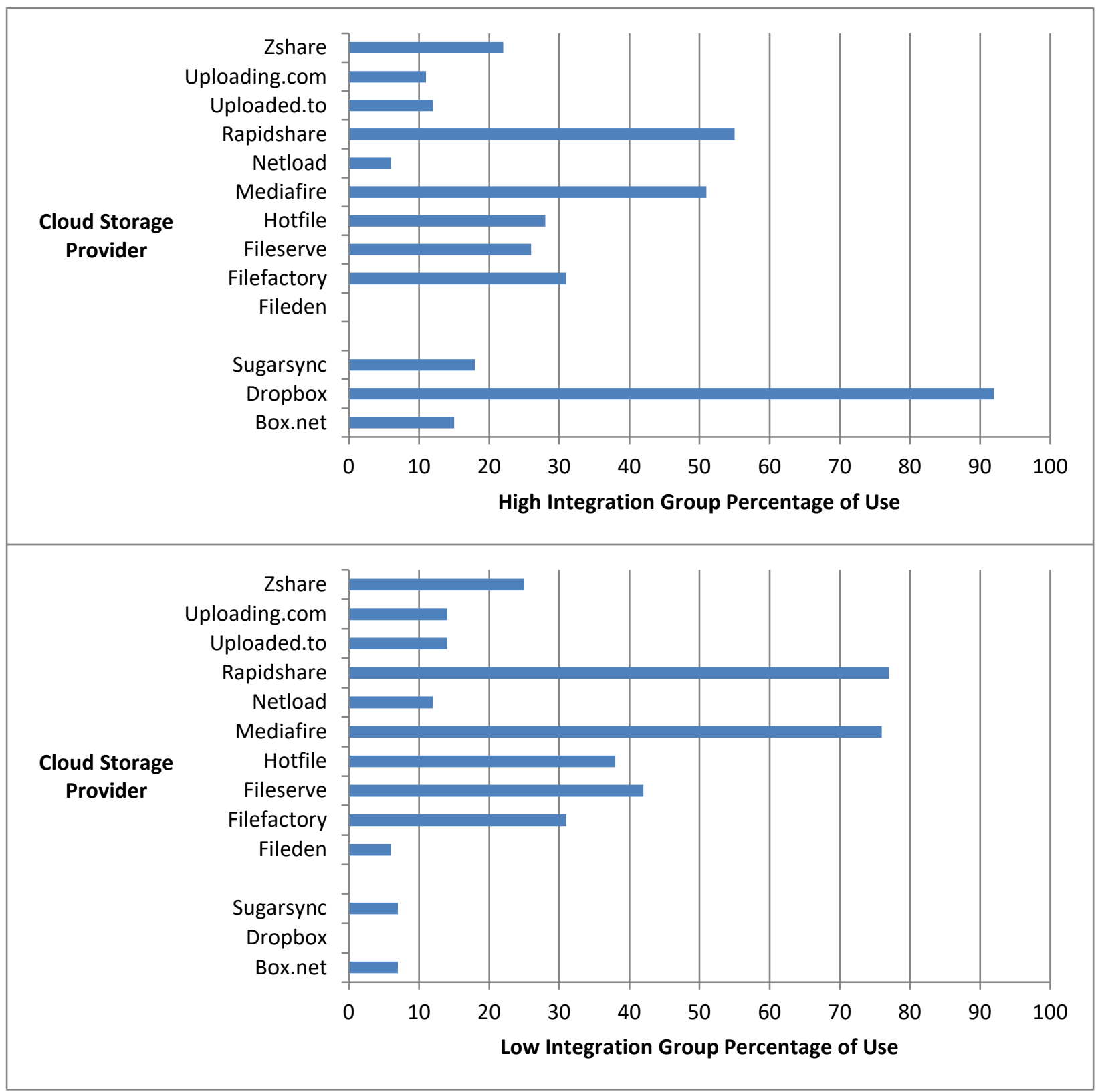

